\title{
Seroprevalence of Toxoplasma gondii among School Children in Pyin Oo Lwin and Naung Cho, Upper Myanmar
}

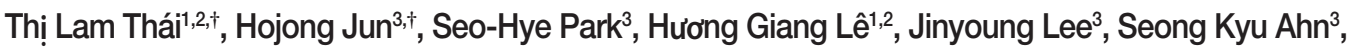 \\ Jung-Mi Kang ${ }^{1,2}$, Moe Kyaw Myint ${ }^{4}$, Khin Lin', Woon-Mok Sohn', Ho-Woo Nam ${ }^{5}$, Byoung-Kuk Na ${ }^{1,2, *}$, Tong-Soo Kim, \\ ${ }^{1}$ Department of Parasitology and Tropical Medicine, and Institute of Health Sciences, Gyeongsang National University School of Medicine, Jinju \\ 52727, Korea; ${ }^{2}$ BK21Plus Team for Anti-aging Biotechnology and Industry, Department of Convergence Medical Science, Gyeongsang National \\ University, Jinju 52727, Korea; ${ }^{3}$ Department of Tropical Medicine, and Inha Research Institute for Medical Sciences, Inha University School of \\ Medicine, Incheon 22212, Korea; ${ }^{4}$ Department of Medical Research Pyin Oo Lwin Branch, Pyin Oo Lwin, Myanmar; ${ }^{5}$ Department of Parasitology, \\ College of Medicine, Catholic University of Korea, Seoul 06591, Korea
}

\begin{abstract}
Toxoplasma gondii is an apicomplexan parasite that can cause toxoplasmosis in a wide range of warm-blooded animals including humans. In this study, we analyzed seroprevalence of $T$. gondii among 467 school children living in the rural areas of Pyin Oo Lwin and Naung Cho, Myanmar. The overall seroprevalence of $T$. gondii among school children was $23.5 \%$; $22.5 \%$ of children were positive for $T$. gondii IgG, $0.4 \%$ of children were positive for $T$. gondii IgM, and $0.6 \%$ of children were positive for both $T$. gondii $\operatorname{lgG}$ and $\operatorname{lgM}$. Geographical factors did not significantly affect the seroprevalence frequency between Pyin Oo Lwin and Naung Cho, Myanmar. No significant difference was found between males (22.2\%) and females (25.0\%). The overall seroprevalence among school children differed by ages (10 years old [13.6\%], 11-12 years old [19.8\%], 13-14 years old [24.6\%], and 15-16 years old [28.0\%]), however, the result was not significant. Polymerase chain reaction analysis for T. gondii B1 gene for lgG-positive and lgM-positive blood samples were negative, indicating no direct evidence of active infection. These results collectively suggest that $T$. gondii infection among school children in Myanmar was relatively high. Integrated and improved strategies including reinforced education on toxoplasmosis should be implemented to prevent and control T. gondii infection among school children in Myanmar.
\end{abstract}

Key words: Toxoplasma gondii, seroprevalence, lgG, IgM, school child, Myanmar

Toxoplasma gondii is an ubiquitous apicomplexan parasite that can cause toxoplasmosis in a wide range of warm-blooded animals including humans [1,2]. It is prevalent in most areas of the world, and approximately $1 / 3$ of the human population is estimated to be chronically infected with this parasite. The global prevalence of T. gondii human infection varies widely depending on geographic and climatic factors, socioeconomic status, cultural habits and the nutritional customs [3]. Humans are usually infected with the parasite by ingesting tissue cysts in undercooked or raw meat or by consuming food or water contaminated with oocysts shed by cats $[4,5]$. Clinically serious $T$. gondii infection can be acquired by congenital transmission from mother to fetus through the placenta during pregnancy $[4,5]$. Blood transfusion and organ transplanta-

- Received 17 March 2019, revised 6 April 2019, accepted 25 April 2019.

*Corresponding authors (bkna@gnu.ac.kr; tongsookim@inha.ac.kr)

${ }^{\dagger}$ These authors contributed equally to this study.

(c) 2019, Korean Society for Parasitology and Tropical Medicine

This is an Open Access article distributed under the terms of the Creative Commons Attribution Non-Commercial License (http://creativecommons.org/licenses/by-nc/4.0) which permits unrestricted non-commercial use, distribution, and reproduction in any medium, provided the original work is properly cited. tion are also potential routes of transmission [1,2]. T. gondii infection is usually asymptomatic or induces only mild clinical symptoms in immunocompetent adults and children; however, it can result in diverse clinical manifestations such as lymphadenitis, meningoencephalitis, or ocular toxoplasmosis in immunocompromised patients. Congenital transmission can lead to serious clinical consequences such as intracranial calcification, mental retardation, chronic chorioretinitis, hydrocephalus, and even fetal death $[2,6]$.

Serological tests for T. gondii-specific antibodies are one of the most commonly used laboratory diagnostic methods for toxoplasmosis as an initial screening approach. Immunoglobulin M (IgM) antibody has been proposed as a marker of acute infection as this antibody usually appears in 1 week after the initial exposure [7]. IgM antibody level increases in a short period, declines gradually, and maintains for several months. On the other hand, IgG antibody is usually produced at several weeks after the initial infection and provides long-term protection. Therefore, the detection of specific IgM antibodies followed by specific IgG antibodies has been established for the 
diagnosis of recently acquired toxoplasmosis [7]. Seroprevalence studies of $T$. gondii infection among school children have been conducted in several countries including Brazil, China, Iran, Mexico, Nigeria, the Republic of the Marshall Islands, the United Arab Emirates (UAE) and the United States of America (USA) [8-16]. It is important to conduct prevalence study in school children since the infected children can manifest symptomatic toxoplasmosis later in life, even if they do not present symptoms at present. Nevertheless, serologic studies of T. gondii infection in school children are limited in Myanmar. This study aimed to evaluate the seroprevalence of $T$. gondii among school children living in the rural areas of Pyin Oo Lwin and Naung Cho in Myanmar on 2017.

A total of 467 blood samples were collected from school children in 4 basic education high schools in Pyin Oo Lwin $\left(22^{\circ} 02^{\prime} 21.04^{\prime \prime} \mathrm{N}, 96^{\circ} 28^{\prime} 17.97^{\prime \prime} \mathrm{E}\right)$, Mandalay Division, and 3 basic education high schools in Naung Cho (22 $19^{\prime} 52.76^{\prime \prime} \mathrm{N}$, $96^{\circ} 48^{\prime} 00.97^{\prime \prime}$ E), Shan State, Myanmar, in August and December 2017 (Fig. 1). Written informed consent was obtained from all children or legal guidances before blood collection. Basic information, including gender, address, and age were also obtained. The age of the children enrolled in this study ranged from 10 to 16 years old. Approximately $1 \mathrm{ml}$ of venous blood was drawn from each participant, labeled individually, and cooled with ice packs to maintain the temperature at $4^{\circ} \mathrm{C}$ during transportation to the laboratory. The serum was separated from the whole blood by centrifugation at 3,000 rpm for $5 \mathrm{~min}$ and stored at $-76^{\circ} \mathrm{C}$ until use. The study protocol was reviewed and approved by the Ethics Committee of the Ministry of Health, Myanmar (97/Ethics 2015), and the Biomedical Research Ethics Review Board of Inha University School of Medicine, Republic of Korea (INHA 15-013).

All serum samples were screened for anti-T. gondii IgG and IgM antibodies by enzyme-linked immunosorbent assay (ELISA). The ELISA kits used in this study were the Human AntiToxoplasma gondii IgG ELISA Kit (Abcam, Cambridge, UK) and the Human Anti-Toxoplasma gondii IgM ELISA Kit (Abcam). All ELISA processes were performed following the manufacturer's instructions. The optical density (OD) values were read at 450 nm using the Multiskan ${ }^{\mathrm{Tm}}$ FC Microplate Photometer (Thermo Scientific, Waltham, Massachusetts, USA). An OD value similar to or greater than the threshold value was considered positive.

Blood samples were further analyzed by molecular method to detect active T. gondii infection. Genomic DNA was extracted from $200 \mu$ of whole blood samples using the QIAamp Blood Kit (Qiagen, Valencia, California, USA) according to the manufacturer's instructions. The DNA samples were evaluated

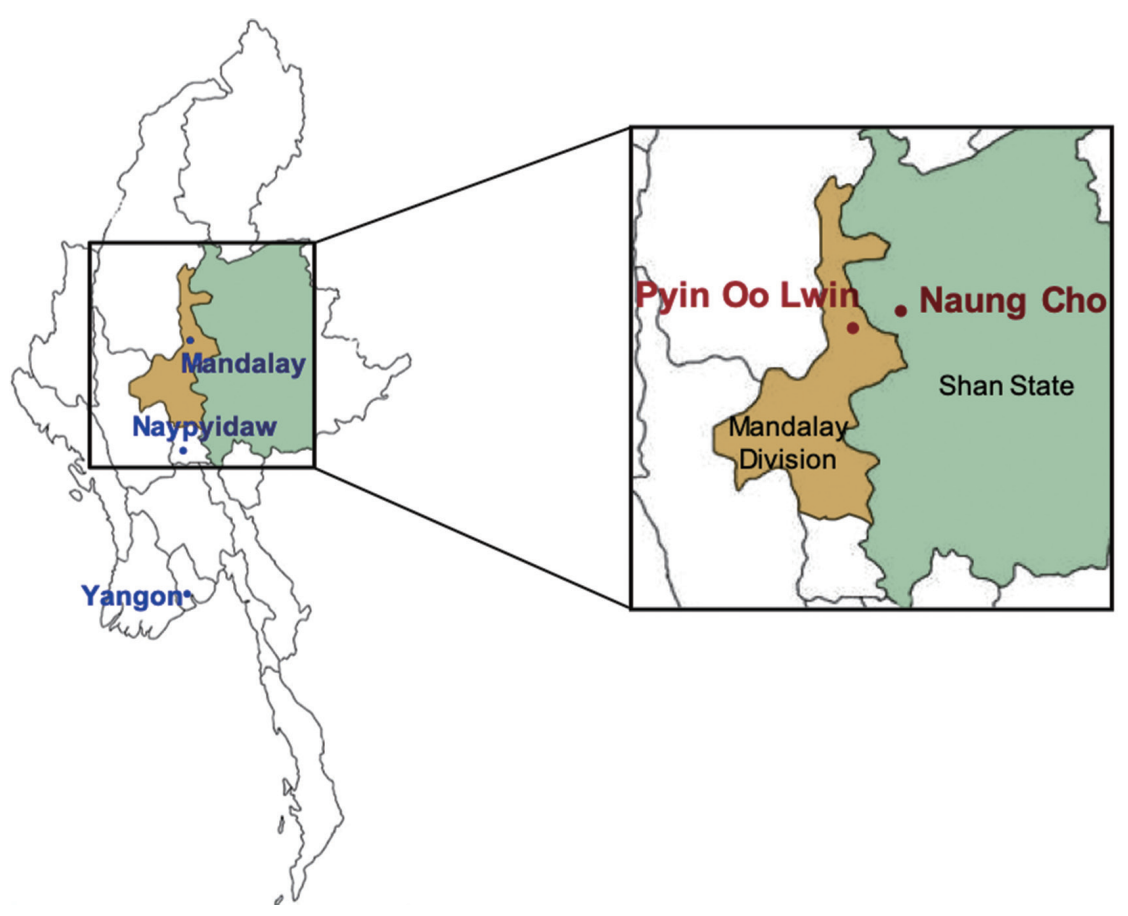

Fig. 1. Map of the study areas. Community-based survey for anti-Toxoplasma gondii antibodies was performed. 
by polymerase chain reaction (PCR) targeting the $T$. gondii $\mathrm{B} 1$ gene using the primers, Toxo-B5 (5'-TGAAGAGAGGAAACAGGTGGTCG- $\left.3^{\prime}\right)$ and Toxo-B6 (5'-CCGCCTCCTTCGTCCGTCGTA-3 ${ }^{\prime}$ ) [17]. The amplification step included 1 cycle of denaturation at $94^{\circ} \mathrm{C}$ for $5 \mathrm{~min}, 35$ cycles of denaturation at $94^{\circ} \mathrm{C}$ for $1 \mathrm{~min}$, annealing at $60^{\circ} \mathrm{C}$ for $1 \mathrm{~min}$, and extension at $72^{\circ} \mathrm{C}$ for $1 \mathrm{~min}$, and a final extension step at $72^{\circ} \mathrm{C}$ for $3 \mathrm{~min}$. In each PCR amplification step, genomic DNA extracted from T. gondii RH strain was included as a positive control. The PCR products were subjected to electrophoresis on a $2 \%$ agarose gel, stained with RedSafe ${ }^{\mathrm{TM}}$ Nucleic Acid Staining Solution (Intron, Seongnam, Korea), and visualized under a UV transilluminator (Analytik Jena US LLC, Upland, California, USA).

Statistical analysis was performed with the SPSS v.20.0 software package (SPSS Inc., Armonk, New York, USA). The relative proportions were calculated using a confidence interval (CI) of 95\%. The Pearson's chi-square and Fisher's extract tests were used to analyze the differences in the seroprevalences of anti-T. gondii IgG and IgM according to sex, age, and area. Odds ratio (OR) with their 95\% CI for various risk factors associated with seropositivity were estimated and $P$-values of $<0.05$ were considered statistically significant.

A total of 467 blood samples collected from school children aged 10-16 years in Myanmar were analyzed for anti-T. gondii IgG and IgM by ELISA. The overall seroprevalence of $T$. gondii was $23.5 \%$; $22.5 \%$ ( $95 \% \mathrm{CI}=18.9-26.4)$ of children were positive for anti-T. gondii $\mathrm{IgG}$ antibodies, $0.4 \%(95 \% \mathrm{CI}=0.1-1.4)$ of children were positive for $\mathrm{IgM}$, and $0.6 \%(95 \% \mathrm{CI}=0.2-1.7)$ of children were positive for both IgG and IgM (Table 1). There was no significant difference in the seroprevalence of $T$. gondii between males $(22.2 \%)$ and females $(25.0 \%)(P=$ 0.480 ) (Table 2). The overall seroprevalence of $T$. gondii was increased with increasing age (Table 2). The prevalence (28.0\%, OR=2.5, 95\% CI = 0.7-9.0) among older school children (15-16-year-olds) showed highest positive serology compared with other groups, 10-year-olds (13.6\%), 11-12-yearolds (19.8\%), and 13-14-year-olds (24.6\%). The seroprevalence of T. gondii among school children in Naung Cho (25.0\%) was slightly higher than that among school children in Pyin Oo Lwin (22.6\%); however, the result was not statistically significant $(P=0.497)$. There was no positive amplification of the T. gondii B1 in all of the seropositive samples.

Myanmar is a country in a subtropical area, and various kinds of parasitic diseases are highly prevalent like other Southeast Asian countries. High humidity and warm climate, which may affect the survival of oocysts of $T$. gondii in the environment [18], may provide the favorable conditions for the development of T. gondii. However, only a few serological studies have been conducted for toxoplasmosis in Myanmar. In this study, the seroprevalence of $T$. gondii among school

Table 1. Seroprevalence of anti-Toxoplasma gondii IgG and IgM antibodies in 467 school children in Naung Cho and Pyin Oo Lwin, Myanmar

\begin{tabular}{lccc}
\hline Antibodies & No. of tested & Positive rate (\%) & Confidence interval (95\%) \\
\hline $\operatorname{lgG}^{+}, \operatorname{lgM}^{-}$ & 105 & 22.5 & $18.9-26.4$ \\
$\operatorname{lgG}^{+}, \operatorname{lgM}^{+}$ & 3 & 0.6 & $0.2-1.7$ \\
$\operatorname{lgG}^{-}, \operatorname{lgM}^{+}$ & 2 & 0.4 & $0.1-1.4$ \\
$\operatorname{lgG}, \operatorname{lgM}^{-}$ & 357 & 76.5 & $72.4-80.1$ \\
Total & 467 & 100.0 & \\
\hline
\end{tabular}

+, positive; -, negative.

Table 2. Socio-demographic characteristics and seroprevalence of Toxoplasma gondii antibody among school children in Naung Cho and Pyin Oo Lwin, Myanmar

\begin{tabular}{|c|c|c|c|c|c|}
\hline Variables & Group & No. of tested & Positive rate (\%) & Odds ratio $(95 \% \mathrm{Cl})$ & $P$-value \\
\hline \multirow[t]{2}{*}{ Gender } & Male & 243 & 22.2 & Referent & \\
\hline & Female & 224 & 25.0 & $1.2(0.8-1.8)$ & 0.48 \\
\hline \multirow[t]{4}{*}{ Age } & 10 & 22 & 13.6 & Referent & \\
\hline & $11-12$ & 121 & 19.8 & $1.6(0.4-5.7)$ & \\
\hline & $13-14$ & 224 & 24.6 & $2.1(0.6-7.2)$ & \\
\hline & $15-16$ & 100 & 28.0 & $2.5(0.7-9.0)$ & 0.34 \\
\hline \multirow[t]{2}{*}{ Geographical region } & Naung Cho & 149 & 25.0 & Referent & \\
\hline & Pyin Oo Lwin & 318 & 22.6 & $0.9(0.5-1.3)$ & 0.497 \\
\hline
\end{tabular}


children living in the rural areas of Pyin Oo Lwin and Naung Cho in Myanmar was investigated on 2017. The prevalence of T. gondii infection is different between countries or communities even in the same region [19]. In this study, the overall seroprevalence of $T$. gondii among the school children in this study was $23.5 \%$ (110/467), which is comparable to that in other studies involving primary school children in southern Nigeria (24.0\%), school children in Iran (22.0\%), and high school students in Mexico $(22.4 \%)[9,10,20]$. Meanwhile, the prevalence in Myanmar was higher than that in other countries including the USA (10.8\%), the UAE (12.5\%), China (16.0\%), Cyrus (6.5\%), and Brazil [14], but much lower than that in West Africa (63.1\%) [11] and the Republic of the Marshall Islands $(54.8 \%)[8,13-15,21]$. The discrepancy in seroprevalence rates between different countries may be attributed to differences in ethnicity, tradition/culture, and food habits [2,3]. Different serodiagnostic methods and sample size may also affect the overall seroprevalence rate of each country. However, the results of this study suggested that $T$. gondii infection among school children in Myanmar should not be ignored. A previous study of the seroprevalence rates of $T$. gondii among school children in Myanmar in 1977 also revealed high levels of T. gondii antibodies in school children in Hlawga (43.8\%) and Gyogon (28.4\%) [22]. It is generally known that there is no gender-related difference in the seroprevalence of toxoplasmosis $[2,23]$. In the present study, the seroprevalence of T. gondii among female children (25.0\%) was slightly higher than that among male children (22.2\%), but not significant $(P=0.480)$. This may be attributed to the similar routes of $T$. gondii infection shared by male and female school children through common risk factors, such as playing in the soil and water or consuming undercooked meat and vegetables. The prevalence of anti-T. gondii antidodies is also known to increase with age $[2,10,13,15,23]$. Consistent with the previous studies, the overall seroprevalence of T. gondii among Myanmar school children was increased with age.

The presence of cats, hygienic conditions, sociocultural habits, and environmental conditions, are closely related to the prevalence of $T$. gondii $[2,23]$. In this study, there was no systematic questionnaire for the school children to access risk factors for T. gondii infection. However, young children are usually vulnerable to $T$. gondii infection due to their behavioral habits, which involve a higher environmental exposure and a lack of awareness for avoiding the risk of infection [12-15]. Substantial levels of T. gondii infections were reported in domestic goats (11.4\%) and wild insectivorous bats $(29.3 \%)[24,25]$ in Myanmar, suggesting widespread T. gondii infection among domestic and wild animals in Myanmar. The ingestion of undercooked meat and unpasteurized milk and cheese from $T$. gondii-infected goats can be a potential cause of infection in humans [26]. Therefore, direct or indirect contact with stray cats or animals, poor hygiene conditions, and consuming undercooked meat and raw vegetables may contribute to T. gondii infection among school children in Myanmar. Congenital transmission cannot be ruled out as a potential source of infection considering the high seroprevalence rate of $T$. gondii among Myanmar pregnant women $[27,28]$. The seroprevalence of T. gondii among refugee and migrant Myanmar pregnant women along the Thailand-Myanmar border reported as $31.7 \%$ [28]. The seroprevalence among Myanmar pregnant women in Yangon was reported as 30.70\% (95\% CI $=27.9$ 37.2) [27]. A lack of awareness of toxoplasmosis is likely to be one of the most key factors contributing to the high prevalence among Myanmar pregnant women. Young girls who are infected with T. gondii in their childhood are not at risk for the transmission of $T$. gondii at the present stage; however, T. gondii infection can cause transplacental transmission when they are pregnant as adults. Therfore, more attention should be given to young girls to prevent any kind of potential transmission in the future. With the rapid spread of HIV/AIDS in Southeast Asian countries [29], toxoplasmosis should be controlled becasue it can lead to life-threatening or fatal conditions. Further studies are necessary to understand the risk factors and possible transmission routes of T. gondii infection in Myanmar school children. Reinforced education to enhance awareness of toxoplasmosis and prevent transmission of the disease also would be necessary for school children in Myanmar.

In conclusion, this is the first community-based survey to analyze the seroprevalence of $T$. gondii among school children in Myanmar. The present study demonstrated the prevalence of T. gondii among the school children with an overall seroprevalence rate of $23.5 \%$. This study highlights the urgent necessity of integrated and improved strategies including public health education for the prevention and control of T. gondii infection in young school children, especially young girls. Additional larger community-based studies in a wide range of geographical locations are also needed to clarify the prevalence rates of toxoplasmosis among school children in Myanmar. 


\section{ACKNOWLEDGMENTS}

The authors would like to thank the staffs in the Department of Medical Research Pyin Oo Lwin Branch and the health professionals in Naung Cho and Pyin Oo Lwin for their contribution and technical support in blood sampling. This study was supported by the National Research Foundation of Korea grant funded by the Korean government (NRF-2017M3A9B8069530).

\section{CONFLICT OF INTEREST}

The authors declare that they have no competing interests.

\section{REFERENCES}

1. Tenter AM, Heckeroth AR, Weiss LM. Toxoplasma gondii: from animals to humans. Int J Parasitol 2000; 30: 1217-1258.

2. Montoya JG, Liesenfeld O. Toxoplasmosis. Lancet 2004; 363: 1965-1976.

3. Flegr J, Prandota J, Sovičková M, Israili ZH. Toxoplasmosis-global threat. Correlation of latent toxoplasmosis with specific disease burden in a set of 88 countries. PLoS One 2014; 9: e90203.

4. Kapperud G, Jenum PA, Stray-Pedersen B, Melby KK, Eskild A, Eng J. Risk factors for Toxoplasma gondii infection in pregnancy. Results of a prospective case-control study in Norway. Am J Epidemiol 1996; 144: 405-412.

5. Jones JL, Muccioli C, Belfort R Jr, Holland GN, Roberts JM, Silveira C. Recently acquired Toxoplasma gondii infection, Brazil. Emerg Infect Dis 2006; 12: 582-587.

6. Rorman E, Zamir CS, Rilkis I, Ben-David H. Congenital toxoplasmosis-prenatal aspects of Toxoplasma gondii infection. Reprod Toxicol 2006; 4: 458-472.

7. Robert-Gangneux F, Dardé ML. Epidemiology of and diagnostic strategies for toxoplasmosis. Clin Microbiol Rev 2012; 25: 264296.

8. Abu-Zeid YA. Serological evidence for remarkably variable prevalence rates of Toxoplasma gondii in children of major residential areas in United Arab Emirates. Acta Trop 2002; 83: 63-69.

9. Galván-Ramíre ML, Pérez LR, Ledesma Agraz SY, Sifuentes Ávila LM. Seroepidemiology of toxoplasmosis in high-school students in the metropolitan area of Guadalajara, Jalisco, Mexico. Sci Medica 2010; 20: 59-63.

10. Sharif M, Daryani A, Barzegar G, Nasrolahei M. Seroepidemiological survey for toxoplasmosis among schoolchildren of Sari, Northern Iran. Trop Biomed 2010; 27: 220-225.

11. Fan CK, Lee LW, Liao CW, Huang YC, Lee YL, Chang YT, da Costa Âdos S, Gil V, Chi LH, Nara T, Tsubouchi A, Akinwale OP. Toxoplasma gondii infection: relationship between seroprevalence and risk factors among primary schoolchildren in the capital areas of Democratic Republic of São Tomé and Príncipe, West Af- rica. Parasit Vectors 2012; 5: 141.

12. Muñoz-Zanzi C, Williams-Nguyen J, Belongia EA, Belongia EA. A sero-survey of toxoplasmosis in farm and non-farm children from Wisconsin, United States, 1997-1999. BMC Public Health 2013; $13: 837$.

13. Fu CJ, Chuang TW, Lin HS, Wu CH, Liu YC, Langinlur MK, Lu MY, Hsiao WW, Fan CK. Toxoplasma gondii infection: seroprevalence and associated risk factors among primary school children in the capital area of the Republic of the Marshall Islands. Jpn J Infect Dis 2014; 67: 405-410.

14. Marchioro AA, Colli CM, Ferreira E'C, Viol BM, Arau'jo SM, Falavigna-Guilherme AL. Risk factors associated with toxoplasmosis and toxocariasis in populations of children from nine cities in southern Brazil. J Helminthol 2015; 89: 428-432.

15. Xin KS, Liu H, Wang HB, Yao ZL. Seroprevalence of Toxoplasma gondii among primary school children in Shandong Province, China. Korean J Parasitol 2015; 53: 489-492.

16. Yang N, Wang D, Xing M, Li C, Li J, Wu A, Sang X, Feng Y, Jiang N, Chen $\mathrm{Q}$. Seroepidemiology and risk factors of Toxoplasma gondii infection among the newly enrolled undergraduates and postgraduate students in China. Front Microbiol 2017; 8: 2092.

17. Gontijo da Silva M, Clare Vinaud M, de Castro AM. Prevalence of toxoplasmosis in pregnant women and vertical transmission of Toxoplasma gondii in patients from basic units of health from Gurupi, Tocantins, Brazil, from 2012 to 2014. PLoS One 2015; 10: e0141700.

18. Meerburg BG, Kijlstra A. Changing climate-changing pathogens: Toxoplasma gondii in North-Western Europe. Parasitol Res 2009; 105: $17-24$.

19. Pappas G, Roussos N, Falagas ME. Toxoplasmosis snapshots: global status of Toxoplasma gondii seroprevalence and implications for pregnancy and congenital toxoplasmosis. Int J Parasitol 2009; 39: 1385-1394.

20. Gyang VP, Akinwale OP, Lee YL, Chuang TW, Orok A, Ajibaye O, Liao CW, Cheng PC, Chou CM, Huang YC, Fan KH, Fan CK. Toxoplasma gondii infection: seroprevalence and associated risk factors among primary schoolchildren in Lagos City, Southern Nigeria. Rev Soc Bras Med Trop 2015; 48: 56-63.

21. Liassides M, Christodoulou V, Moschandreas J, Karagiannis C, Mitis G, Koliou M, Antoniou M. Toxoplasmosis in female high school students, pregnant women and ruminants in Cyprus. Trans R Soc Trop Med Hyg 2016; 110: 359-366.

22. Tin F. Serological responses to Plasmodium and Toxoplasma in school children from two areas in Burma. Southeast Asian J Trop Med Public Health 1977; 8: 552-557.

23. Wilking H, Thamm M, Stark K, Aebischer T, Seeber F. Prevalence, incidence estimations, and risk factors of Toxoplasma gondii infection in Germany: a representative, cross-sectional, serological study. Sci Rep 2016; 6: 22551.

24. Bawm S, Maung WY, Win MY, Thu MJ, Chel HM, Khaing TA, Wai SS, Htun LL, Myaing TT, Tiwananthagorn S, Igarashi M, Karakura K. Serological survey and factors associated with Toxoplasma gondii infection in domestic goats in Myanmar. Scientifica 
(Cairo) 2016; 2016: 4794318.

25. Sun H, Wang Y, Zhang Y, Ge W, Zhang F, He B, Li Z, Fan Q, Wang W, Tu C, Li J, Liu Q. Prevalence and genetic characterization of Toxoplasma gondii in bats in Myanmar. Appl Environ Microbiol 2013; 79: 3526-3528.

26. Dubey JP, Verma SK, Ferreira LR, Oliveira S, Cassinelli AB, Ying Y, Kwok OC, Tuo W, Chiesa OA, Jones JL. Detection and survival of Toxoplasma gondii in milk and cheese from experimentally infected goats. J Food Prot 2014; 77: 1747-1753.

27. Andiappan H, Nissapatorn V, Sawangjaroen N, Nyunt MH, Lau YL, Khaing SL, Aye KM, Mon NC, Tan TC, Kumar T, Onichan- dran S,bin Mat Adenana NA. Comparative study on Toxoplasma infection between Malaysian and Myanmar pregnant women. Parasit Vectors 2014; 7: 564.

28. van Enter BJD, Lau YL, Ling CL, Watthanaworawit W, Sukthana Y, Lee WC, Nosten F, McGready R. Seroprevalence of Toxoplasma gondii infection in refugee and migrant pregnant women along the Thailand-Myanmar border. Am J Trop Med Hyg 2017; 97: 232-235.

29. Pendse R, Gupta S, Yu D, Sarkar S. HIV/AIDS in the South-East Asia region: progress and challenges. J Virus Erad 2016; 2 Suppl 4: 1-6. 